\title{
Els residus en un laboratori de secundària
}

\author{
Miquel Erra i Gallach \\ IES Antoni Pous i Argila (Manlleu) \\ merra@xtec.cat
}

Curs rere curs, es van acumulant en els laboratoris de secundària una gran varietat de reactius amb un grau de toxicitat alt o mig que són un risc per a la nostra salut. Aquests reactius generen alhora residus d'alt cost de tractament que de vegades no es recullen adequadament i van a parar a l'aigüera. Treballar a microescala, utilitzar reactius de la gamma química verda, minimitzar residus i recollir-los adequadament són protocols que cal aplicar.

Paraules clau: microescala, organohalogenats, metalls pesants, química verda, minimització de residus

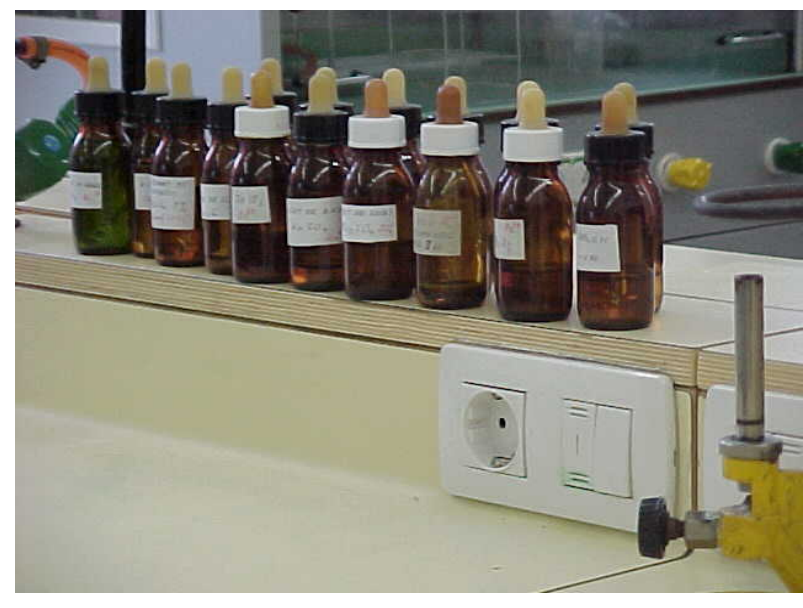

La generació de residus de laboratori en centres de secundària és un problema greu per la gran varietat que se'n genera, per la seva alta i diversa perillositat $i$, especialment, perquè estem treballant amb alumnes mot joves $\mathrm{i}$ inexperts que, per obvi desconeixement, no són conscients del que manipulen. Tanmateix, al Ilarg de la nostra història laboral passem moltes hores en laboratoris majoritàriament poc condicionats. Per aquestes raons de seguretat i salut ens cal plantejar-nos la reestructuració dels nostres laboratoris.

Als laboratoris de química i de biologia del nostre centre hem implantat un programa, amb l'objectiu de minimitzar riscos i exposicions innecessàries, portat a terme en quatre etapes.

\section{Selecció de residus i productes}

És la fase més important. Hem prescindit de les substàncies més perilloses, com els compostos òrganohalogenats, aromàtics (benzè i derivats), mercuri (hem deixat de comprar termòmetres que en continguin) i les seves sals, cianurs i derivats, sulfurs, i una restricció progressiva de metalls pesants.

\section{Minimització de residus}

Practiquem el més important: la reducció en origen. La majoria de les pràctiques de laboratori que realitzem són qualitatives; per això utilitzem solucions diluïdes i guardades en flascons comptagotes. Les reaccions les fem en tubs 0 càpsules molt petites i dosificades gota a gota. D'aquesta manera el consum de reactius és mínim, generem menys residus i la despesa econòmica és menor.

\section{Recollida de residus}

Un cop implantades les etapes anteriors, la recollida des residus generats queda molt simplificada. Nosaltres ho fem d'aquesta manera: 


\section{A. Solucions aquoses}

D'elements dels grups 1 i 2 de la taula periòdica. També solucions d'àcids i bases febles o diluïdes. Si són fortes i concentrades les neutralitzem prèviament.

\section{B. Metalls pesants}

Solucions d'elements que no pertanyen ni al grup 1 ni al 2 de la taula periòdica. En aquest garrafa també hi aboquem les sals de bari.

\section{Oxidants}

Solucions d'oxidants i reductores. Si generem restes enèrgiques, com la mescla cròmica, el recipient ha de ser de vidre.

\section{Dissolvents}

Un cop feta la selecció detallada en l'etapa 1, els dissolvents utilitzats no presenten toxicitats greus i es poden recollir tots junts. Si produïm algun dels altres compostos orgànics, el recollirem en un altre recipient.

Al costat de la balança tenim un recipient petit per recollir els excessos de les pesades.

També tenim altres recipients per a recollir materials que no són considerats residus químics, tals com:

\section{E. Sòlids inerts}

Porcellana, materials ceràmics, metàl-lics, plàstics i polímers en general. Per a qualsevol reactiu sòlid no utilitzem mai una paperera.

\section{F. Paper}

Paper i cartró per reciclar. El tenim situat en un local al costat del laboratori.

\section{G. Vidre}

Tot el material de vidre malmès.

\section{H. Matèria orgànica}

Restes vegetals, cultius biològics, etc. Els cultius es desinfecten prèviament.

\section{Gestió de residus}

És l'etapa més difícil de realitzar degut al seu alt cost econòmic. Nosaltres disposem del suport desinteressat d'una indústria farmacèutica, ubicada al nostre municipi, que ens facilita els serveis del seu gestor de residus. Així, ens recull els recipients de la $A$ fins a la $D$, ens proporciona els recipients $i$ l'etiquetatge i fem un seguiment intern per a conèixer la gestió final dels residus. Els residus dels grups E fins a l'H segueixen el mateix procés que qualsevol residu municipal.

\section{Alternatives}

Si tenim molt clar que els nostres laboratoris no són centres d'investigació ni de control, ràpidament deduirem que no ens calen tants reactius específics d'un cert grau de toxicitat i no sempre les reaccions han de tenir un rendiment del 100\%.

Tanmateix, no hem deixat de fer cap pràctica representativa. Com a exemples n'indicarem algunes:

\section{Determinació del punt de fusió}

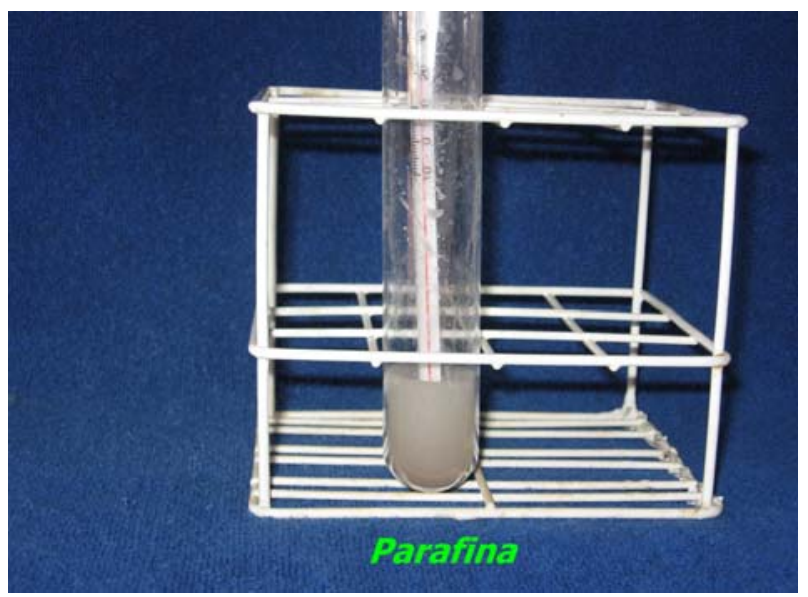

Utilitzem parafina, en lloc del para-diclorobenzè, en la determinació del punt de fusió. La parafina comercial té un punt de fusió entorn dels $60^{\circ} \mathrm{C}$, temperatura molt adequada per treballar al bany maria. Ja guardem tubs de Buscarons preparats $i$ sempre fem servir els mateixos.

\section{Sublimació}

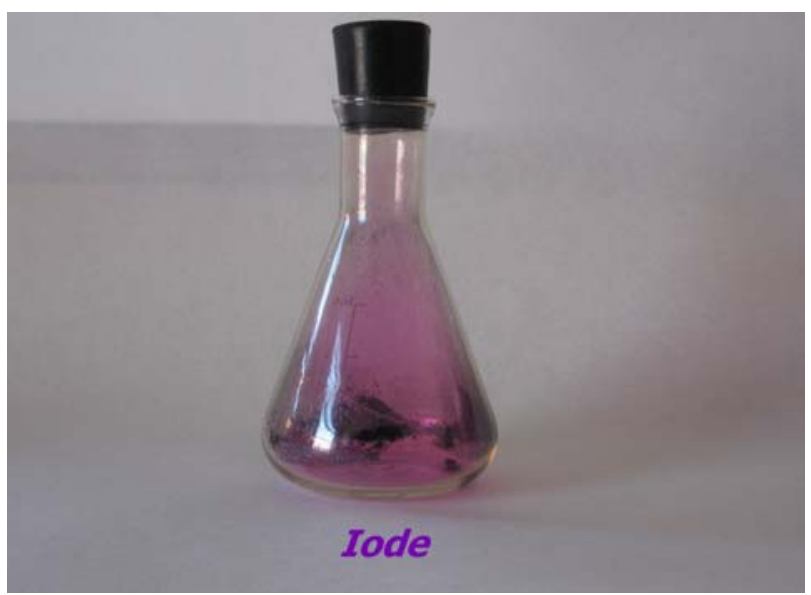


En coptes d'àcid benzoic, per a la sublimació es pot utilitzar iode en petites quantitats. El iode el guardem en un erlenmeyer ben tapat i ens serveix per altres vegades.

\section{Extracció}

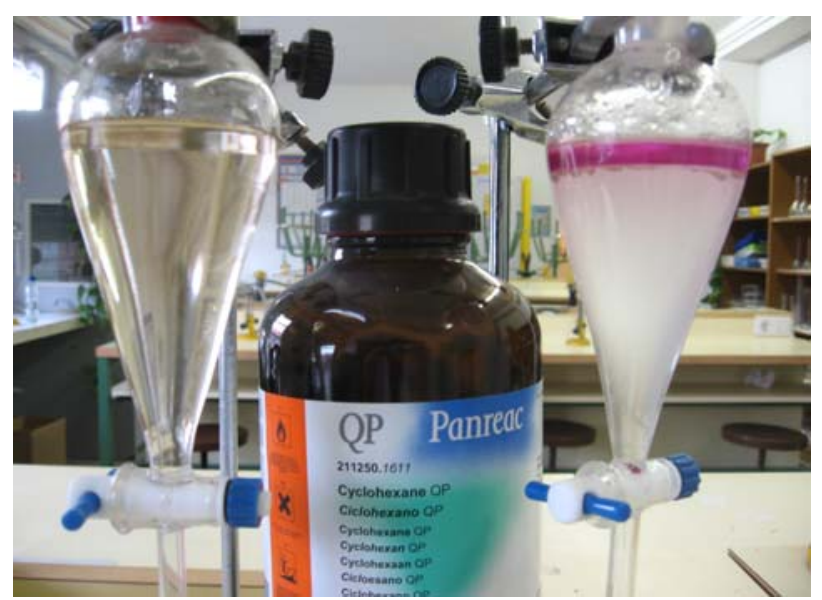

En la pràctica d'extracció del iode en aigua iodada utilitzem ciclohexà o bé èter de petroli (malgrat el seu nom, és una mescla d'hidrocarburs, principalment $n$-pentà i 2-metilpentà). Ambdós són bons dissolvents del iode, tot i que siguin menys densos que el tetraclorur de carboni, usat majoritàriament en aquesta pràctica, però no tan tòxics.

\section{Cromatografia de plantes verdes}

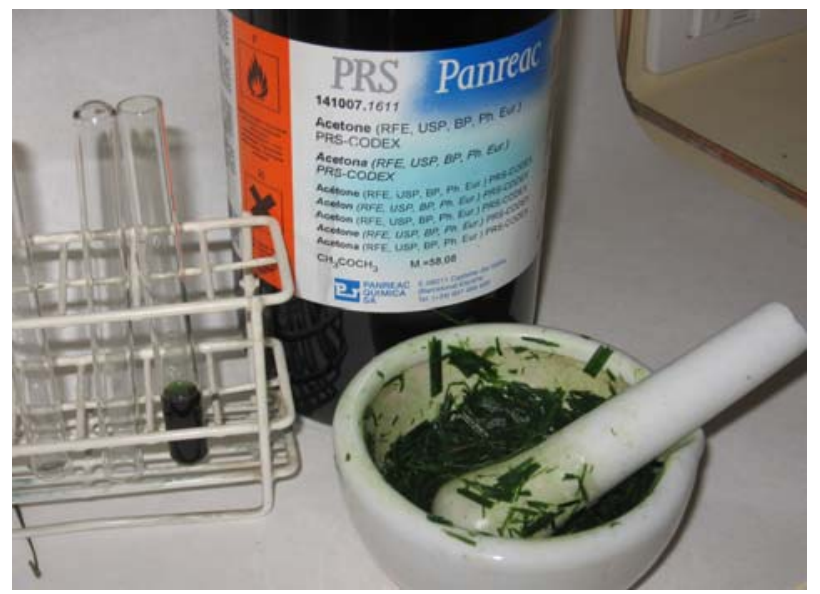

L'acetona funciona prou bé per fer un extracte de fulles de gespa, per exemple, i es poden veure els quatre pigments principals: les clorofil.les A i B, els carotens i la xantofil-la, en cromatografia de capa fina.

\section{Matèria orgànica}

Pel que fa a l'anàlisi d'aigües, en comptes de fer la DQO fem la matèria orgànica amb permanganat molt diluït, etc. Amb una mica d'imaginació i unes quantes proves prèvies es van trobant alternatives i, el més important, l'ambient del laboratori és més sa.

\section{Reaccions de precipitació}

Habitualment se solen utilitzar sals de metalls pesants, com el plom. En aquest tipus de pràctiques utilitzem sals de calci i de magnesi.

\section{Termòmetres}

Sempre s'acaben trencant i si són de mercuri tenim un risc de toxicitat afegit. El seus vapors són perillosos i costa de recollir completament les gotetes encara que se'n faci una pasta, tal com indiquen els manuals. Resolem aquest problema utilitzant termòmetres d'èter, vermells o blaus. No són tan precisos però l'error que mesurem no afecta la metodologia usada ni l'aprenentatge dels alumnes.

\section{Finalment}

Utilitzem reactius poc nocius, en petites dosis $\mathrm{i}$ solucions diluïdes. Pel que fa a dissolvents, usem alcohols de cadena curta (el metanol només en cremadors), acetona, ciclohexà i èter de petroli.

Per netejar les taules, utilitzem el fregalls típics d'una cuina i les eixuguem amb draps. No utilitzem paper.

Per ambientar el laboratori hi tenim plantes, com el potus, que ens sanegen l'aire que respirem. També hi posem una mica de música de fons que ens ajuda a treballar en un ambient més acollidor.

Resumint, la filosofia que apliquem als nostres laboratoris, és:

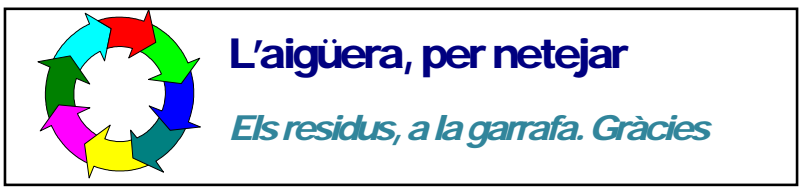

Els alumnes no llencen cap residu a l'aigüera, és un hàbit que ràpidament aprenen i que sempre dóna bones satisfaccions. 


\section{Agraïments}

Volem agrair les gestions fetes per l'ajuntament de Manlleu, l'assessorament rebut de l'anterior Junta de Residus i especialment a la inestimable col.laboració de l'empresa Almirall Prodesfarma. Sense el seu suport difícilment hauríem pogut realitzar una bona gestió global dels nostres residus. 